\title{
Mastectomy skin flap thickness
}

Dear Editor,

We are writing in response to your very interesting recent publication in September 2017 entitled "Multidisciplinary international survey of post-operative radiation therapy practices after nipplesparing or skin-sparing mastectomy" by Marta et al (EJSO 43 (2017) 2036 - 2043), and the subsequent excellent Editorials in November 2017 by Dr Abram Recht MD and Dr Isabel Rubio MD, respectively. This was a large survey evaluating opinions on the need for post-mastectomy radiotherapy after skin-sparing or nipple-sparing mastectomy. The authors quite rightly raise the very important issue of how thick a mastectomy skin flap should be raised, in order to remove sufficient breast tissue for oncological safety, whilst preserving viable skin flaps.

In Table 5 of the paper (page 2041), the survey asks "After skin-sparing mastectomy / nipple-sparing mastectomy, what residual breast tissue can be left behind. What amount of residual tissue do you consider as acceptable in the context of an oncological surgery?" Interestingly, over $50 \%$ of respondents said that they did not know, or "none of the above." $28.5 \%$ said $1-5 \mathrm{~mm}, 10.7 \%$ said 6 $10 \mathrm{~mm}$, and $4.4 \%$ said $11 \mathrm{~mm}-20 \mathrm{~mm}$. However, we did not think it was clear, whether the thickness being asked for represented actual residual breast tissue, or rather the thickness of the skin flaps, which also contain dermis, subcutaneous adipose tissue and fascia. We therefore thought it might be helpful to share some further anatomical information on the subject, already within the published literature, to help further inform this interesting discussion. This is based on the findings of two literature reviews we have recently published [1,2].

Several anatomical and histological studies have been performed (references within [1]) revealing that a subcutaneous layer of variable thickness (ranging from $0.4 \mathrm{~mm}$ to $29 \mathrm{~mm}$ ) lies between the dermis and breast tissue. The thickness of this layer does seem to vary within the breast, and also between the same pair of breasts, and does not reliably appear to be associated with obesity or patient age. This layer primarily consists of adipose tissue, but may also contain fascia, with islands of breast tissue within. The precise architecture and existence of a distinct layer of superficial fascia in the breast remains controversial, and may only be present in up to $56 \%$ of patients. When present, the fascia may not be visible macroscopically. Over the last 70 years, histological studies of mastectomy specimens and mastectomy skin flaps have consistently revealed that it is not possible to remove all breast tissue at mastectomy, despite total glandular excision being the purported goal. Furthermore, mastectomy skin flap necrosis occurs in upto a third of cases in the literature (references within [2]), and so a balance must be sought between removing as much breast tissue as possible at mastectomy, whilst leaving reliably viable skin flaps.

Whilst the meta-analysis of observational studies by Lanitis et al [3] in 2010 indicated no difference in Local Recurrence Rates (LRR) between skin-sparing versus simple mastectomy, there have been some recent reports, including one in this journal by Al-Himdani et al [4], suggesting a possible increased LRR with skin-sparing versus simple mastectomy. Given the devastating effects for patients of potentially developing a local recurrence after mastectomy on the one hand if residual disease is left, and of skin flap necrosis on the other hand if skin flap viability is threatened, this topic quite rightly deserves the increased scrutiny it is receiving.

With Many Thanks, 
Yours Sincerely,

Stuart A Robertson

University Hospital Coventry and Warwickshire NHS Trust, Clifford Bridge Road, Coventry, CV2 2DX, UK.

Telephone: 02476965275 Email: stuart.robertson@uhcw.nhs.uk

\section{Ramsey I Cutress}

University of Southampton and University Hospital Southampton Foundation Trust, Somers Cancer Sciences Building, Tremona Road, Southampton SO16 6YD, UK.

Telephone: 02381205723 Email: r.i.cutress@soton.ac.uk

References:

[1] Robertson SA, Rusby JE, Cutress RI. Determinants of optimal mastectomy skin flap thickness. Br J Surg 2014; 101: 899-911

[2] Robertson SA, Jeevaratnam JA, Agrawal A, Cutress RI. Mastectomy skin flap necrosis: challenges and solutions. Breast Cancer (Dove Med Press) 2017; 9: 141-152

[3] Lanitis S, Tekkis PP, Sgourakis G, Dimopoulos N, Al Mufti R, Hadjiminas DJ. Comparison of skin-sparing mastectomy versus non-skin-sparing mastectomy for breast cancer: a meta-analysis of observational studies. Ann Surg 2010; 251: 632-639

[4] Al-Himdani S, Timbrell S, Tan KT, Morris J, Bundred NJ. Prediction of margin involvement and local recurrence after skin-sparing and simple mastectomy. Eur J Surg Onc 2016; 42(7): 935-41 